\title{
PRONATEC E MUNDO DO TRABALHO: QUALIFICAÇÃO PROFISSIONAL PARA O MERCADO DA INFORMALIDADE?
}

\section{PRONATEC AND THE WORLD OF WORK: PROFESSIONAL QUALIFICATION FOR MARKET INFORMALITY?}

\author{
Maria Luzirene Oliveira do Nascimento ${ }^{1}$
}

\section{RESUMO}

Este texto propõe uma discussão sobre o Programa Nacional de Acesso ao Ensino Técnico e ao Emprego - Pronatec no âmbito da relação trabalho e educação, vez que o trabalho é condição intrínseca a existência humana. Partimos dessa compreensão para abordar as reflexões desse estudo e apresentar a dupla face do trabalho diante da sociabilidade contemporânea, tomando como fundamento a concepção marxiana e as contradições que se estabeleceram ao longo da acumulação do capital. Estas análises se fazem relevantes diante da problematização sobre para qual mercado de trabalho se qualifica mão de obra no Pronatec. Diante das contradições que dicotomizam trabalho e desemprego no capitalismo, abordamos o setor informal e as formas precárias, em que, contraditoriamente, o trabalho é tido como um direito social, pois o Estado deveria promover políticas de acesso ao emprego. Essa discussão permeia o contexto do Pronatec, pois este programa faz parte de uma política de educação profissional que visa à qualificação e a inserção do sujeito no mundo do trabalho.

Palavras - chave: Trabalho - Educação - Qualificação Profissional Informalidade.

\begin{abstract}
This text proposes a discussion of the National Program for Access to Technical Education and Employment - Pronatec in the context of labor relations and education, since the work is intrinsic condition of human existence. We start this understanding to address the reflections of this study and present the doublesided work on the contemporary sociability, taking as a basis the Marxian conception and contradictions that settled over the capital accumulation. These analyzes are made relevant in the face of questioning about what to labor market qualifies labor in Pronatec. Faced with the contradictions that dichotomize work and unemployment in capitalism, we address the informal sector and precarious forms, in which, paradoxically, the work is considered a social right because the state should promote access to employment policies. This discussion permeates the Pronatec context, as this program is part of a vocational training policy which aims at qualifying and the inclusion of the subject in the world of work.
\end{abstract}

Keywords: Work - Education - Professional Qualification - Informality.

\section{INTRODUÇÃO}


Este estudo tem como objetivo discutir o Programa Nacional de Acesso ao Ensino Técnico e ao Emprego - Pronatec na perspectiva de compreender a relação trabalho e educação que permeia a qualificação profissional. Apresentamos a compreensão de trabalho como categoria intrínseca á produção da materialidade da existência humana e as formas de apropriação deste pelo modelo de produção capitalista. Analisamos as contradições que permeiam essa categoria, e a necessidade de qualificação de mão de obra demandada por este modelo de sociedade. Assim, apresentamos o trabalho a partir da sua dupla face entre trabalho humano concreto e trabalho produtivo abstrato.

Para tanto, buscamos analisar o trabalho enquanto elemento ontológico de construção da sociabilidade humana e a apropriação deste pelo modelo capitalista de produção. A fim de compreender as contradições que envolvem 0 trabalho no mundo contemporâneo. A partir dessa contextualização buscamos problematizar sobre a qualificação da mão de obra para este mercado, e os programas que veem sendo implantados como políticas de qualificação profissional e promessa de acesso ao emprego no Brasil durante o governo Dilma (2010 a 2014). Neste contexto, é que analisamos o Pronatec e suas configurações na relação trabalho e educação, considerando o trabalho como um direito social, contraditoriamente, apropriado como mercadoria e espaço de disputa social e ideológica.

O Pronatec é um programa criado no governo Dilma (2010 a 2014), que vem sendo implantado desde 2012, através do Decreto № 12.513, de 26 de Outubro de 2011. Tem como finalidade ampliar a oferta de educação profissional e tecnológica, por meio de programas, projetos e ações de assistência técnica e financeira. O referido Programa oferta cursos na modalidade técnica de nível médio e formação inicial e continuada. Articula-se diretamente com a necessidade de qualificação de mão de obra para 0 mercado de trabalho, tendo como um de seus objetivos ampliarem as oportunidades educacionais dos trabalhadores, por meio do incremento da formação e qualificação profissional.

Diante da relação trabalho e educação que permeia a proposta do Pronatec problematizamos sobre qual mercado de trabalho e qual 
trabalhador este programa está qualificando mão de obra. Abordamos a concepção de trabalho como direito, a noção de empregabilidade que permeia esse contexto e a necessidade do sistema capitalista criar alternativas para absorver mão de obra numa sociedade do desemprego estrutural, criando subterfúgios através do mercado informal.

Diante dessa problemática, nos fundamentamos a partir de teóricos como Marx (1982), Antunes (1995), Albornoz (2008), Cacciamali (2000), Assis (2002). A reflexão a cerca do mercado da informalidade se fundamenta sob a compreensão de que a condição de empregabilidade nessa sociedade relaciona-se as diversas estratégias do mercado de trabalho em absorver mão de obra. Assim a empregabilidade se refere a um contexto em que o indivíduo deve manter-se adaptável e qualificado para um mundo do trabalho em constante mutação.

O contexto das transformações político e econômicas nos remete à necessidade de qualificação profissional e as formas de reorganização do trabalho no capitalismo. A situação de desemprego perpassa as formas de reestruturação do capital e necessidade de expandir o mercado de consumo. Estes indicadores influenciam a demanda por qualificação profissional que demanda a necessidade do Estado promover política e programas de acesso ao ensino técnico, a exemplo do Pronatec.

\title{
SENTIDOS E METAMORFOSES DO TRABALHO: ENTRE A EMANCIPAÇÃO E O TRIPALIUM DO CAPITALISMO
}

\begin{abstract}
Paradoxal é que no mesmo século em que construímos instrumentos fantásticos que é o cérebro eletrônico, as imensas possibilidades de um magnífico progresso de conhecimento, fruto de muito trabalho humano, se vão frustrar em uma tecnologia destrutiva da natureza e distanciada da felicidade dos homens.
\end{abstract}

(ALBORNOZ, 2008, p. 22)

A compreensão de trabalho no capitalismo difere em muitos aspectos da concepção de trabalho geral, trabalho concreto que possibilita ao homem a construção da sua sociabilidade, das suas condições materiais de existência, enquanto trabalho indissociável da condição humana. Desde o 
limiar da relação capital e trabalho, este último se constituiu enquanto elemento fundamental do processo produtivo, mas não somente no sentido de promover a sobrevivência do homem enquanto sujeito do processo do trabalho, mas para promover o desenvolvimento dos meios de produção e acumulação do capital.

Para tanto, devemos compreender a dupla face do trabalho, que inicialmente nos remete a categoria trabalho em seu sentido ontológico, no qual o homem produz a si e a suas condições de sobrevivência através dele. Para Marx (1999, p. 10) "ao produzirem seus meios de existência, os homens produzem indiretamente a sua própria vida material." A maneira como os homens produzem seus meios de existência depende das condições matérias da sua produção. E ao produzirem materialmente sua existência os homens transformam a natureza, isto ocorre através do trabalho realizado que interfere na relação do homem com o meio.

De acordo com Marx (1999) o trabalho é elemento fundamental que diferencia o homem dos outros animais, pois antes de realizar qualquer trabalho 0 homem tem a capacidade teleológica de antecipar mentalmente a sua atividade e interferir no ambiente:

\begin{abstract}
A aranha realiza operações que lembram o tecelão, e as caixas suspensas que as abelhas constroem envergonham o trabalho de muitos arquitetos. Mas até mesmo o pior dos arquitetos difere de início, da mais hábil das abelhas, pelo fato de que, antes de fazer uma caixa de madeira, ele já a construiu mentalmente. No final do processo ele obtém um resultado que já existia em sua mente antes de ele começar a construir. $O$ arquiteto não só modifica forma que the foi dada pela natureza, dentro das restrições impostas por ela, como também realiza um plano que Ihe é próprio, definindo os meios o caráter da atividade aos quais ele deve subordinar sua vontade. (MARX, 2013, p. 15)
\end{abstract}

Portanto, o trabalho é elemento indissociável da vida humana. $\mathrm{Na}$ perspectiva marxiana envolve a produção da materialidade da existência humana a partir da sua relação com a natureza desde seus primórdios, e perpassa o desenrolar da história da humanidade e sua construção social. Desde condição ontológica, o conceito de trabalho em Marx, compreende a totalidade das relações sociais como categoria fundante do ser social e atividade inerente ao ser humano que o distingue de outros animais, 
Atividade útil que busca a apropriação dos produtos da natureza sob uma ou outra forma, o trabalho é a condição natural da existência humana, a condição, independente de todas as formas sociais, do intercâmbio da matéria entre o homem e a natureza. Ao contrário, o trabalho que cria valor de troca é uma forma de trabalho especificamente social. [...] O legislador Moisés sabia tão bem como Adam Smith, o inspetor aduaneiro, que o trabalho é uma fonte de riqueza material (MARX, 2008, p. 62/63).

O trabalho deve constituir-se como fonte de realização humana, vez que, é através deste que os homens constroem a sua própria história e produzem seus meios de vida, ou seja, as condições materiais de que necessitam para sobreviver. Para Marx (2013), "o trabalho é, antes de mais, um processo entre homem e Natureza, um processo em que o homem medeia, regula e controla a sua troca material com a Natureza através da sua própria ação". Nessa perspectiva, portanto, o trabalho deve ser expressão da criatividade e emancipação humana, pois "o que eles [os homens] são coincide com sua produção, tanto com o que produzem, como com o modo como produzem" (MARX \& ENGELS, 1982, p. 27/28), assim, é que o trabalho se apresenta como condição indissociável da construção da vida humana e social.

No entanto, no modelo de produção capitalista o trabalho é apropriado como mercadoria e se confunde com o objeto produzido, fruto da força de trabalho humana, ora como trabalho vivo, ora como trabalho morto. Para Albornoz

"na submissão do trabalho ao capital a força de trabalho é dada como uma mercadoria. Do esforço do operário é extraído um valor que deixa uma sobra os interesses do capital, pois o salário do operário fica muito aquém do valor que ele cria para o mercado" (ALBORNOZ, 2008, p. 40).

O trabalho corporificado torna-se uma mercadoria, tanto quanto o sujeito que o produz, pois de acordo com Marx

$\mathrm{O}$ trabalhador torna-se uma mercadoria ainda mais barata à medida que cria mais bens. A desvalorização do mundo humano aumenta na razão direta do aumento de valor do mundo dos objetos. O trabalho não cria apenas objetos; ele também se produz a si mesmo e ao trabalhador como uma mercadoria, e, deveras, na mesma proporção em que produz bens. Esse fato simplesmente subentende que o objeto produzido pelo trabalho, o seu produto, agora se the opõe como um ser estranho, como uma força independente do produtor. (MARX, 2013, p. 23.) 
Isto porque o trabalho no sistema capitalista é um mecanismo intercambiante de troca e acumulação de riquezas concentrada nas mãos de poucas pessoas, onde o trabalhador que detém sua força de trabalho vendea em troca de um salário aos donos dos meios de produção. Nessa concepção o trabalho torna-se alienado, ou seja, alheio ao próprio trabalhador que se distancia da totalidade do sentido do seu trabalho e o torna uma mercadoria comercializável tanto quanto os produtos que esse trabalho alienado produz. Segundo Albornoz (2008, p.34) "o trabalho é alienado do trabalhador porque o produtor não detém, não possui nem domina os meios de produção".

Mesmo os meios de produção tendo se desenvolvido ao longo da história do capitalismo, o trabalho ainda se constitui condição elementar para o processo produtivo nesse sistema, pois é através dele e por meio dele que o homem transforma a matéria em objetos dotados de sentidos e significados. Como, por exemplo, na fabricação de uma cadeira, esta é carregada de significados, pois no seu processo produtivo ela utilizou trabalho vivo, por traz da produção da cadeira existem diversos elementos que contribuíram para que a cadeira se transformasse no que ela é, e o principal elemento que possibilitou a transformação de uma matéria prima qualquer em uma cadeira foi o trabalho.

Nessa compreensão o próprio trabalho é dotado de significados. De acordo com Albornoz (2008) o trabalho tem vários significados, a definição de trabalho está relacionada ao contexto social e histórico:

Às vezes lembra dor, tortura, suor do rosto, fadiga. Noutras designa a operação humana de transformação da matéria natural em objeto de cultura. É o homem em ação para sobreviver e realizar-se, criando instrumentos, e com esses, todo um novo universo cujas vinculações com a natureza, embora inegáveis, se tornam opacas. (ALBORNOZ, 2008, p. 08)

O trabalho na contemporaneidade não expressa uma condição de realização humana, os significados que carrega está relacionado à condição de apropriação da força de trabalho pelo capital. O que o torna uma atividade exaustiva, dolorosa. De acordo com Antunes (2005, p. 11) "com o evolver humano, o trabalho se converteu em tripaliare - originário de tripalium, instrumento de tortura -, momento de punição e sofrimento" e para 
o trabalhador só os poucos momentos que não está trabalhando lhe causa alguma satisfação ou prazer, somente nos momentos de lazer, onde se encontra distante do ambiente de trabalho o trabalhador se reconhece enquanto ser humano.

Comumente, na contemporaneidade, a noção de trabalho muitas vezes se confunde com o emprego, o que devemos atentar para o fato de que são duas categorias diferentes, pois enquanto trabalho é uma condição inerente ao homem, o emprego é uma situação socialmente determinada que implica ter condições e direitos assegurados. Diante das metamorfoses do capitalismo contemporâneo alguns teóricos tem apresentado a tese do fim da sociedade do trabalho, em que ressalvadas as diferenças entre eles, todos comungam com a ideia de que o trabalho, hoje, não é mais a categoria sociológica central. No entanto, para Silva e Leite (1996, p.41) ao contrário das expectativas colocadas por Offe ao apontar "o fim da categoria trabalho como conceito sociológico fundamental, o estudo do trabalho está no centro das atenções dos sociólogos".

Esta concepção remete-se à confusão que se faz entre trabalho e emprego, no entanto, como falar em crise da sociedade do trabalho se necessitamos, cotidianamente, dele para a construção da materialidade da nossa existência, que mesmo no âmbito da relação capital e trabalho se constitui elemento fundamental para impulsionar o processo produtivo. De acordo com Antunes (2005)

\begin{abstract}
Podemos afirmar que as teses que defendem o fim da centralidade do trabalho, como traço constitutivo da chamada "crise da sociedade do trabalho", sua substituição pela esfera comunicacional ou da intersubjetividade encontram seu contraponto quando se parte de uma concepção abrangente e ampliada de trabalho, que contempla tanto sua dimensão coletiva quanto subjetiva, tanto na esfera do trabalho produtivo quanto improdutivo, tanto material quanto imaterial, bem como nas formas assumidas pela divisão sexual do trabalho, pela nova configuração da classe trabalhadora, entre os vários elementos aqui apresentados. (ANTUNES, 2005, p. 38).
\end{abstract}

Nesse sentido, falar da crise da sociedade do trabalho seria apontar uma crise da própria existência humana. Além disso, nunca se trabalhou tanto como diante da lógica de produtividade, consumismo, competitividade e exploração cada vez mais intensa da força de trabalho no 
âmbito do capitalismo contemporâneo. Como falar do fim da sociedade do trabalho, se é o trabalho vivo ou morto que move as bases produtivas do capital? Se há milhões de desempregados e despossuídos a procura de um emprego para sobreviver, pois somente através do trabalho, mesmo apropriado pelo capital, poderão garantir suas condições mínimas de sobrevivência?

O que vivemos na verdade é uma crise na sociedade do emprego, com perdas de direitos no modelo de trabalho assalariado, onde na lógica capitalista permanece metamorfoseando-se sob as formas de trabalho precarizado, part-time ${ }^{2}$, terceirizado, material ou imaterial. Outro aspecto da composição decorrente do processo de reestruturação da produção é a demanda nos setores de serviços maior do que nas indústrias.

Essa discussão nos remete ao contexto de implantação do Pronatec ao considerarmos que este programa surge em meio à necessidade de qualificação profissional para atender a novas demandas do mundo do trabalho. O Pronatec visa assegurar a qualificação profissional e 0 acesso ao emprego, o que se configura não somente como um emprego assalariado, mas também que o público desse programa se qualifique e desenvolva habilidades para se inserir no mercado de trabalho que se apresenta também na forma de trabalho informal.

A concepção de trabalho informal, ou melhor, designada por Cacciamali (2000) de setor informal, é expressa na condição de proprietários e trabalhadores que participam de uma produção em unidades produtivas micro ou pequenas, onde a relação capital-trabalho não se encontra bem estabelecida, seja na organização do trabalho ou no cumprimento das regras legais. Mas envolve ainda uma série de transformações político-econômicas em âmbito mundial e local que determinam as condições de trabalho e desregulamentação do setor formal de oferta de emprego. Estas transformações se referem ao processo de reestruturação produtiva que se inicia, no âmbito da organização do trabalho, com a crise do modelo fordista de produção: 
A crise do fordismo e as consequentes tentativas de superação que a ela se seguiram significam um conjunto de mudanças econômicas, políticas e sociais que atingiram rapidamente, e de maneira profunda, praticamente todos os cantos do mundo. (LEITE \& SILVA, 1996, p. 45)

Estas transformações no capitalismo exigem que o trabalhador busque alternativas para se inserir nesse mercado, através de cursos de qualificação, muitas vezes aligeirados que lhe garantam a possibilidade de manter-se empregável no mundo do trabalho. Além disso, empresas, organizações empresarias, e o próprio Estado promovem oferta de cursos de qualificação como, por exemplo, os cursos do Pronatec.

No âmbito do Estado do Piauí, nos dados disponibilizados pela Secretaria de Educação do Piauí - SEDUC, as principais instituições que compõem o Sistema S aparecem com maior número de vagas e oferta na modalidade Formação inicial continuada (FIC) e técnica no período de 2011 a 2013. Com destaque para o Serviço Nacional de Aprendizagem que em 2013 ofertou 8.879 vagas, concentrando o maior número de vagas dentre as instituições apresentadas no quadro abaixo.

Tabela 1: Dados PRONATEC

\begin{tabular}{|c|c|c|c|c|c|c|c|c|c|}
\hline \multirow{3}{*}{ OFERTANTE } & \multirow{2}{*}{\multicolumn{3}{|c|}{$\mathbf{N}^{0}$ de VAGAS }} & \multicolumn{6}{|c|}{ OFERTA } \\
\hline & & & & \multicolumn{2}{|c|}{2011} & \multicolumn{2}{|c|}{2012} & \multicolumn{2}{|c|}{2013} \\
\hline & 2011 & 2012 & 2013 & FIC & TÉC & FIC & TÉC & FIC & TÉC \\
\hline $\begin{array}{l}\text { Serviço Nacional de Aprendizagem } \\
\text { Comercial - SENAC }\end{array}$ & 4084 & 9685 & 8879 & 36 & 09 & 21 & - & 332 & 44 \\
\hline $\begin{array}{l}\text { Serviço Nacional de Aprendizagem } \\
\text { Industrial - SENAI }\end{array}$ & 862 & 794 & 2042 & 09 & 02 & 21 & - & 118 & - \\
\hline Instituto Federal do Piauí - IFPI & 4186 & 5266 & 2561 & 46 & 11 & 36 & - & 27 & 14 \\
\hline $\begin{array}{l}\text { Serviço Nacional de Aprendizagem } \\
\text { Rural - SENAR }\end{array}$ & - & 240 & 750 & 10 & - & - & - & 50 & - \\
\hline $\begin{array}{l}\text { Serviço Nacional de Aprendizagem do } \\
\text { Transporte }\end{array}$ & - & - & 285 & & & & & 13 & - \\
\hline $\begin{array}{l}\text { Secretaria da Educação e Cultura do } \\
\text { Piauí }\end{array}$ & - & 880 & 2748 & - & 03 & - & - & - & 08 \\
\hline Colégio Agrícola de Bom Jesus & - & 820 & 2110 & 09 & 04 & - & - & 22 & 04 \\
\hline Colégio Agrícola de Floriano & - & 240 & 750 & 06 & - & - & - & 13 & 7 \\
\hline Colégio Agrícola de Teresina & - & 400 & 1183 & 10 & - & - & - & 17 & 6 \\
\hline TOTAL & 9.132 & 18.325 & 21.308 & 126 & 29 & 78 & - & 592 & 83 \\
\hline
\end{tabular}

Fonte: PRONATEC/SEDUC

Nesse quadro podemos constatar o crescimento do número de vagas desde 2011, ano da criação do programa, até 2013. Houve um crescimento da 
oferta em todas as instituições, de forma mais acentuada na modalidade de Formação Inicial e Continuada. Mas podemos observar que as instituições que compõem o Sistema $S$ apresentam o maior número de vagas e de oferta, dentre todas as instituições, com exceção do SENAT, com um número de vagas e oferta menor do que o Instituto Federal do Piauí.

No Piauí a Secretaria Estadual de Educação é um dos órgãos que são ofertantes e demandantes dos cursos do Pronatec, para alunos matriculados na rede pública de ensino. A preocupação com a qualificação de mão de obra é um fenômeno inerante ás metamorfoses do mundo do trabalho, que se expressam na possiblidade do trabalhador manter-se empregável. A preocupação do Estado em promover políticas e programas de qualificação profissional surge da necessidade de uma resposta ao desemprego e miséria social, atrelada à falsa concepção de que a educação é o mártir capaz de resolver estes problemas sociais, inclusive, possibilitar a entrada no mercado de trabalho.

Atrelada a essa situação, no setor informal é onde se encontram frequentemente pessoas menos qualificadas e com menores salários, pois um dos fenômenos que envolvem o setor informal é o auto emprego, que de acordo com Cacciamali,

\footnotetext{
"são estratégias de sobrevivência empreendidas por pessoas que, por apresentarem dificuldades de reemprego ou de ingresso no mercado de trabalho, ou por opção, auferem renda através de formas de trabalho por conta própria." (CACCIAMALI, 2000 p. 164).
}

A relação desse fenômeno com os cursos do Pronatec se dá na medida em que se propaga a ideia de formar uma cultura do empreendedor, ao ofertarem cursos como administração de empresas e formações pelo Sebrae. Inclui-se também nessa perspectiva a formação continuada para trabalhadores que já se encontram no setor informal, como forma de certificar o saber construído através do trabalho.

A Educação Profissional permeada do ideário neoliberal e constituída enquanto propulsora do desenvolvimento social e econômico da nação tem cumprido o papel de política compensatória para a inclusão na informalidade (SALES, 2012), dentre muitas outras, como programas de incentivo ao empreendedorismo e de financiamento, que oferece créditoao pequeno empreendedor, muitas vezes, oriundo do setor informal incentivado a se tornar um microempreendedor. 
O trabalho na sociabilidade contemporânea tornou-se uma condição intrínseca do processo de produção no capitalismo, sendo que este sistema sustenta a desigualdade social na sua essência, é necessário que o Estado assegure direitos sociais para promover condições mínimas de dignidade e cidadania. Assim, o trabalho condição inerente à existência do homem nessa sociedade passa a se reivindicar também como um direito. Compreender o trabalho como um direito nesse contexto nos leva a reflexão sobre o conceito de cidadania e a relação do trabalho com a concepção de empregabilidade.

A cidadania no capitalismo é um elemento da divisão estrutural de classes desse sistema. Para quem e o que se configura como cidadania numa sociedade que nega direitos sociais mínimos de sobrevivência humana, como por exemplo, ter acesso a alimentar-se, vestir-se, ter uma moradia? A condição animal do homem torna-se elemento principal de sua existência, pois o acesso a outros espaços de emancipação humana são limitados aos, mas pobres. Aos que tem acesso apenas ao básico a sua sobrevivência não pode desfrutar de espaços que possibilitem cultivar a arte, a ciência, ou seja, emancipar-se. Há ainda neste sistema, os que não têm acesso nem mesmo ao necessário para sobreviver. Daí o papel do Estado promover políticas de assistência a esse público.

O conceito de cidadania perpassa todos esses indicadores sociais, inclusive, a atividade produtiva que um sujeito exerce nessa sociedade. A empregabilidade nesse sistema é um dos fatores determinantes da condição de cidadania, pois é através do trabalho e pelo trabalho que o homem se insere na vida social. É o trabalho assalariado e/ou apropriado no processo produtivo que lhe dá condições de se tornar um consumidor de bens e serviços oferecidos pelo mercado. A quantidade de bens e serviços que um indivíduo tem acesso nessa sociedade determina sua situação de cidadania. De acordo com Assis (2002)

O direito ao trabalho remunerado surge na história moderna em algumas Constituições contemporâneas como contrapartida necessária do direito de propriedade privada, ambos constituindo fundamentos da cidadania nas democracias representativas; para o cidadão não proprietário, esse direito está em um plano equivalente ao do direito de propriedade para os proprietários (ASSIS, 2002, p. 103)

A compreensão do trabalho como um direito na sociabilidade do capital se remete ao trabalho assalariado, pois constituiu uma condição de cidadania ampliada, 
difundida com as medidas intervencionistas propostas pelo keynesianismo no século XX, principalmente, após a década de 1929, como possibilidade de conter a crise do estado capitalista. No contexto dessas políticas Assis (2002, p.103) analisa que:

\begin{abstract}
O direito de propriedade implicou a cidadania (limitada), enquanto a cidadania (ampliada) implicou o direito ao trabalho remunerado. A expressãço prática deste último foi o Estado do bem-estar social, promovido no após-guerra sob a liderança dos partidos de tendências socialistas nos Estados Unidos, na Europa Ocidental, na Austrália e no Japão. (ASSIS, 2002, p. 103)
\end{abstract}

No Brasil essa concepção surge, timidamente, com 0 Estado desenvolvimentista. Pois com o avanço do processo de urbanização do país surgiram demandas crescentes das massas que se defrontavam com um padrão de desenvolvimento que não possibilitava uma distribuição de renda, e aumentava a miséria, ocasionada pelo desemprego e baixos níveis de salário. Para Assis (2002, p.103) "no Brasil, o reconhecimento da cidadania ampliada é um fenômeno tardio (1988)". Mas que impulsionou o Estado a tomar medidas intervencionistas como a promoção de políticas de acesso e promoção de emprego e renda.

É nessa perspectiva que surge, por exemplo, o Pronatec (Programa Nacional de Acesso ao Ensino Técnico e ao Emprego) tem sido executado e idealizado como um programa para inserir os sujeitos no mercado e capaz de combater o desemprego, que habilite o trabalhador em uma profissão e/ou atividade rentável e produtiva para o desenvolvimento econômico e social, sendo também uma proposta de qualificação de mão de obra necessária ao mundo do trabalho.

No entanto, com as novas formas de organização do trabalho, o advento do neoliberalismo, desregulamentação do mercado se acentua a diminuição do trabalho assalariado e o aumento do setor informal que reflete na condição de cidadania.

De acordo com Cacciamali (2000)

\footnotetext{
"a apreensão de diferentes formas de participação na produção e a análise das contradições concretas do uso da força de trabalho são de fundamental importância para avaliar as circunstâncias de reprodução da população, da definição e do evolver da cidadania" (CACCIAMALI, 2000).
}

O trabalho na era da informatização se contrasta com a informalidade, que surge em meio às adversidades do cotidiano de trabalhadores que não encontram vaga no mercado de trabalho e buscam no setor informal uma alternativa de sobrevivência, funcionando como uma forma de envernizar o mal estar do capitalismo diante da miséria e do desemprego. A situação de informalidade era característica dos 
países periféricos durante a hegemonia do modelo taylorista/fordista, no entanto no processo de transição para o modelo de acumulação flexível essa situação começa a se expandir também nos países mais desenvolvidos, decorrente do enxugamento da mão de obra nas indústrias, da fragmentação do operariado e da modificação dos contratos. O trabalho informal foi sendo apropriado pela lógica produtivista e se constituindo importante para a manutenção da sociedade capitalista na medida em que se condicionou à acumulação de riquezas.

Não obstante, o trabalho informal já existia antes do processo de reestruturação e da acumulação flexível advindo das transformações da década de 1970 (SALES, 2012), a informalidade é um fenômeno anterior ao processo de reestruturação produtiva, embora em realidades distintas nos países centrais comparados aos países subdesenvolvidos, no entanto esse meio foi afetado pela reestruturação produtiva com o advento das formas de subcontratação e terceirização, e passou a se configurar na relação capital-trabalho e nas formas de precarização do trabalhador.

Diante dessa compreensão a empregabilidade é um termo utilizado tanto no sentido de trabalho assalariado, formal, regularizado como para o trabalho informal, precarizado, part-time que mesmo não possibilitando o acesso a garantias sociais, produzem renda. Nessa concepção é que a empregabilidade é um disfarce da sociedade do desemprego, pois:

\footnotetext{
O drama social do desemprego no Brasil começa pelo massacramento de sua expressão real por limitações estatísticas. O IBGE, responsável pela apuração do índice oficial de desemprego urbano, só o faz regularmente para as seis maiores regiões metropolitanas. $O$ índice oficial mensal de desemprego refere-se ao que se poderia chamar de desocupação absoluta, isto é, a situação na qual, no período de referência (semana ou mês) a pessoa não exerceu nenhuma atividade. Se tiver vendido pastéis na praia no fim de semana é considerada ocupada. (ASSIS, 2002, p. 96)
}

O debate sobre qualificação do trabalhador perpassa todos esses indicadores de demanda de empregabilidade relacionadas as transformações socioeconômicas e políticas. Diante desse contexto, os cursos do Pronatec são ofertados de forma a atender um público em situação de desemprego e de vulnerabilidade social, como técnico para quem concluiu o ensino médio, com duração mínima de um ano; Técnico para quem está matriculado no ensino médio, com duração mínima de um ano; Formação Inicial e Continuada ou qualificação profissional, para trabalhadores, estudantes de ensino médio e beneficiários de programas federais de transferência de renda, com duração mínima de dois meses. 
Esse público em situação de desemprego ou vulnerabilidade social é mão de obra barata a um mercado de trabalho que cria fundos de reserva.

\section{CONSIDERAÇÕES FINAIS}

Diante das reflexões apresentadas neste estudo o trabalho torna-se, portanto, uma categoria importante para a análise da temática do Pronatec, considerando as contradições geradas pelo capital, ao propor qualificação de mão de obra para o mundo do trabalho. Contradições estas decorrentes da apropriação do trabalho como mercadoria no âmbito do modelo de produção capitalista, que em momentos de crise procura alternativas de reestruturação e organização do trabalho para sustentar esse sistema de desigualdade e exploração da força de trabalho.

Foi possível apreender dessa investigação, em confluência com a teoria marxiana, que o trabalho na sociabilidade do capital constitui ao mesmo tempo uma forma de construção social e negação do homem enquanto gênero humano, pois as relações de trabalho apropriadas pelo capital desumaniza a própria atividade humana como havia postulado Marx no século XIX. Assim, os cursos de qualificação ao se adequar a esse sistema visam qualificar um trabalhador que seja empregável, tenha competências para se inserir no mercado de trabalho, negligenciando a formação do homem enquanto um sujeito completo.

Isto porque, o próprio processo de trabalho no âmbito do capital se descaracteriza como uma condição de realização humana, intrínseca ao ser humano, e funciona apenas como instrumento de potencialização das forças produtivas do capital. Nesse processo o homem confunde-se com o próprio instrumento de trabalho, se torna tão coisa quanto à coisa que produz. No entanto, devemos compreender que é possível pensar num outro modelo de construção da sociabilidade, que possibilidade a construção de significados do trabalho para além da lógica do capital.

Pois este modelo não consegue absorver a mão de obra disponível, tendo que criar condições de empregabilidade para o público que egresso dos cursos técnicos. Porém, ao contrário da ideologia que enxerga a educação como responsável pela inserção no mundo do trabalho, devemos atentar para o falto de que a educação sozinha não consegue gerar políticas de emprego e renda.

Não estamos, contudo, negando a necessidade de qualificação profissional e tampouco sua importância no contexto de um sistema que exige trabalhador qualificado. Mas é necessário um atento olhar a um projeto mais amplo para além da 
implantação de programas e políticas de educação profissional para suplantar a condição de sociedade do desemprego e da informalidade em que vivemos. Pois, concomitantemente, a implantação do Pronatec como programa que visa qualificar o trabalhador através de cursos técnicos, é necessária promover políticas de emprego e renda para os egressos destes cursos, para minimamente, amenizar a situação de miséria social, vez que, as contradições continuarão se acirrando nesse sistema que sobrevive da desigualdade social e acumulação de riquezas nas mãos de poucas pessoas.

\section{REFERÊNCIAS BIBLIOGRÁFICAS}

ANTUNES, Ricardo. O caracol e sua concha: ensaios sobre a nova morfologia do trabalho. São Paulo: Boimtempo, 2005.

Adeus ao trabalho? As metamorfoses e a centralidade do mundo do trabalho. Ed. Boitempo, 1995.

ALBORNOZ, S. O que é trabalho. São Paulo: Brasiliense, 2008.

ASSIS, J. Carlos de. Trabalho como direito: fundamentos para uma política de promoção ao pleno emprego no Brasil. Rio de Janeiro: contraponto, 2002.

BRASIL, Ministério da Educação. Políticas públicas para a Educação Profissional e Tecnológica.

Disponível em: http://portal.mec.gov.br/setec/arquivos/pdf/p_publicas.pdf. Acesso em: 27 de dezembro de 2014.

Tecnológica.

Ministério da Educação. Secretaria de Educação Profissional e http://portal.mec.gov.br/setec/arquivos/pdf/p_publicas.pdf. Acesso em 27 de dezembro de 2014.

CACCIAMALI, Maria C. Globalização e processo de informalidade. In: Economia e Sociedade. Campinas: UNICAMP. Instituto de Economia, n.14, Jun. 2000.

LEITE, Marcia de Paula. SILVA, Roque Aparecida da. A Sociologia do Trabalho frente à reestruturação produtiva: um discussão teórica. Rio de Janeiro, n. 42, 2ำ semestre de 1996.

MARX, Karl. O capital. Disponível em: http://www.marxists.org/. Acesso em: 15 de fevereiro de 2013.

. Manuscritos

Revista LABOR

Econômicos Filosóficos. Disponível em: 
www.marxists.org/portugues/marx/. Acesso em: 16 de fevereiro de 2013.

. Contribuição à crítica da economia política. Tradução e introdução de Florestan Fernandes. 2 ed. São Paulo: Expressão Popular, 2008.

O Capital-crítica de economia política - livro primeiro: o processo de produção do capital. 17. Ed. Rio de Janeiro: Civilização Brasileira, 1999. v.1.

ENGELS, Friedrich. A ideologia alemã. $3^{\text {a }}$ ed. Livraria Editora Ciências Humanas. São Paulo, 1982.

PIAUÍ. Relatório Analítico da Superintendência de Ensino-SEDUC. Teresina-PI: 2013

SALES, Francisco. PLANFOR: Política compensatória para a "inclusão" na informalidade. Fortaleza: Edições UFC, 2011.

\footnotetext{
${ }^{1}$ Mestranda em Educação UFPI/PPGED

2 Trabalho parcial que segundo Antunes (2005) o sistema capitalista necessita cada vez menos de trabalho estável e cada vez mais de trabalho parcial, ou seja, part - time. Trabalho esse precarizado, terceirizado e que se encontra em expansão em todo o mundo produtivo e de serviços.
}

RECEBIDO EM: Julho de 2015

APROVADO EM: Julho de 2015 